\title{
European Journal of
}

\section{Technology}

(EJT)

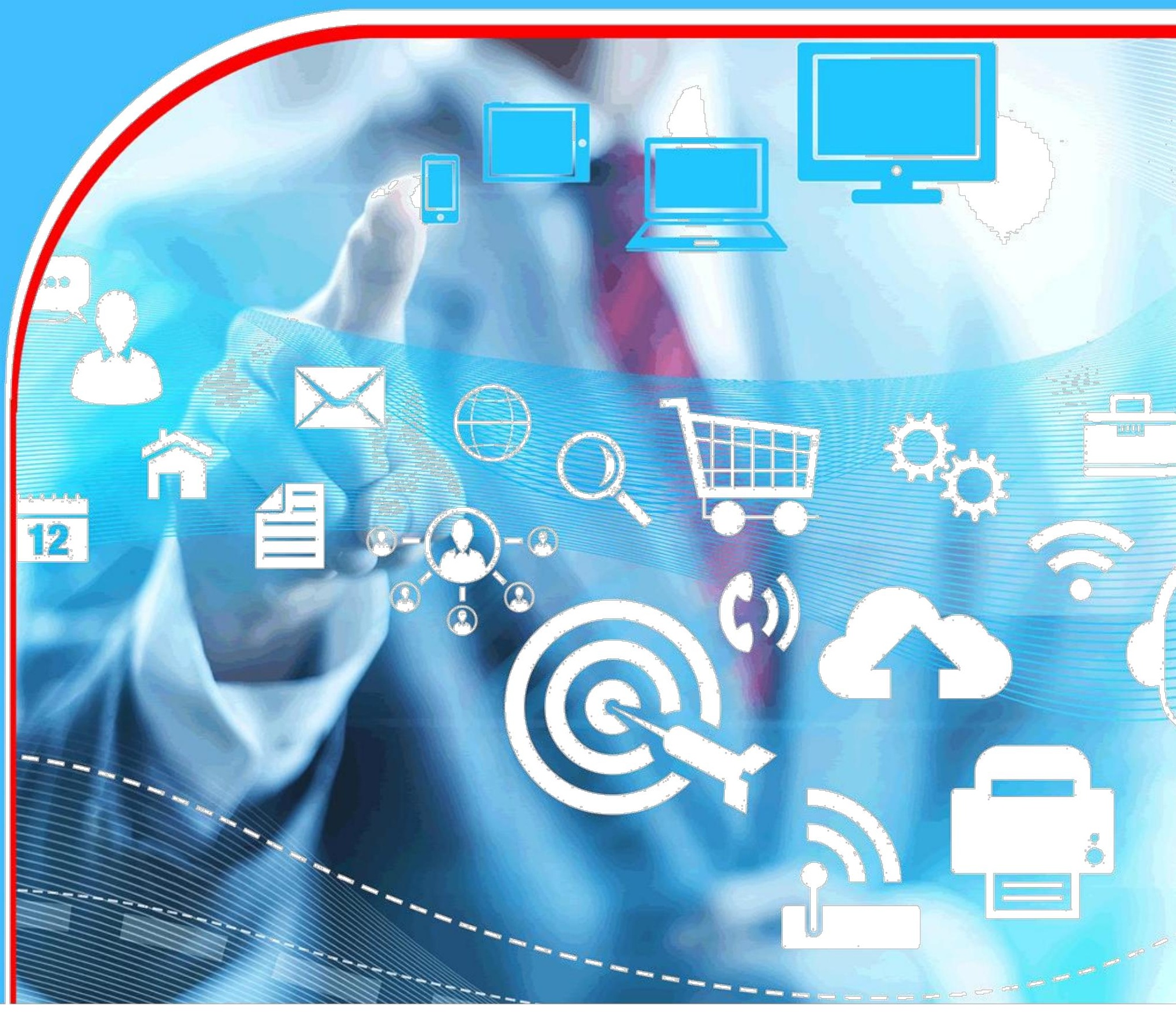

EFFECTIVENESS OF BUSINESS INTELLIGENCE

TECHNOLOGY ABSORPTIVE CAPACITY AND INNOVATION COMPETENCY OF UNIVERSITY STAFF, CASE OF UGANDA CHRISTIAN UNIVERSITY MBALE CAMPUS

Fred Wauyo, Edwin Omol, James Okumu 


\title{
EFFECTIVENESS OF BUSINESS INTELLIGENCE TECHNOLOGY ABSORPTIVE CAPACITY AND INNOVATION COMPETENCY OF UNIVERSITY STAFF, CASE OF UGANDA CHRISTIAN UNIVERSITY MBALE CAMPUS
}

\author{
${ }^{1 *}$ Fred Wauyo \\ Dean, School of Computing and Information Technology Livingstone International \\ University Uganda \\ *Corresponding Author's Email: wauyofredricks@gmail.com \\ ${ }^{2}$ Edwin Omol \\ Research Scholar, Department of Information and Communication Technology Kisii \\ University Kenya \\ Corresponding Email: omoledwin@gmail.com \\ ${ }^{3}$ James Okumu
}

Lecturer, School of Computing and Information Technology Livingstone International University Uganda

Corresponding Email: nyakwarowala@gmail.com

\begin{abstract}
Purpose: the purpose of the study was to explore the extent of business intelligence technology on absorptive capacity, the level of innovative competence of University staffs, the relationship between the extent of business intelligence technology, absorptive capacity, the level of innovative competence among University staff, formulated development programs based on the study findings and established profile of respondents in terms of age, gender, educational level and length of service.
\end{abstract}

Methodology: A descriptive cross sectional survey design guided the study and primary data was collected using structured questionnaires. Respondents classified into strata from which they were chosen randomly. The study population was 150 and a sample size of 108 got using sloven's formula for generating sample size. Research data was organized according to research questions and by category of respondents of the study. The results were analyzed using SPSS. The responses to different questions were quantified into frequencies mean, translated into percentages and ranks and presented in tables.

Results: The study revealed the following findings; majority of respondents were male, degree holders and most of the respondents served below 3 years. The extent of business intelligence technology Level ranged from high, moderate to very low, majority of staff's level of innovative competence high and there was a significant relationship between business intelligence technology, absorptive capacity and level of innovative competence and the null hypothesis was rejected.

Unique contribution to theory, practice and policy: The study recommends that the university's top management needs to support the staff in various ways that will not only build their absorptive capacity but improve upon their skills and competencies in preparation for adoption of business intelligence technology (BIT) in the university.

Keywords: Business Intelligence Technology (BIT), absorptive capacity, innovative competence of University staffs 
European Journal of Technology

ISSN 2520-0712 (Online)

Vol.1, Issue 2 No.4, pp55-73, 2017

\subsection{INTRODUCTION}

\subsection{Background of the Study}

Business Intelligence (BI) Technologies is becoming vital for many organizations, especially those that have extremely large amount of data. Decision makers depend on detailed and accurate information when they have to make decisions. Business Intelligence Technology (BIT) can provide decision makers with such accurate information, and with the appropriate tools for data analysis.Business Intelligence Technology (BIT) is an umbrella term that combines architectures, tools, data bases, applications, practices, and methodologies. Gartner Group (1996) defined BIT as "information and applications available broadly to employees, consultants, customers, suppliers, and the public. The key to thriving in a competitive marketplace is staying ahead of the competition.

Business intelligences technologies (BIT) emphasize the repetitive approach required to successfully extract maximum benefit from investment in Business Intelligence. It is repetitive because the Business Intelligence Technology (BIT) solutions evolve as the business evolves and offers much benefit to businesses. Similarly, Business Intelligence Technology (BIT) projects are often mistakenly seen as purely technology based, with ownership limited to Information Technology (IT) specialists within the business instead of being embedded throughout the organization (Parkinson2010). Failing to address underlying data issues can easily lead to problems in delivering Business Intelligence Technology (BIT), as well as an unwillingness to challenge the existing status quo. Because staff members tend to look at Business Intelligence Technology (BIT) as purely Information Technology (IT) based, they fear to adopt and use such facilities offered by Business Intelligence Technology (BIT) (Heyns 2010).

The lack of timely access to information latency is one of the most difficult challenges to using business intelligence technology (BIT) systems successfully. However, the decision latency that prevails in old Business Intelligence Technology (BIT) environments was unacceptable in environments where decisions may affect business operations on the day they are made (Sharda 2007). It is further noted by Shariat (2007), that most employees are inefficient and less productive in their organizations. Organizations try to provide necessary facilities that are supposed to help them perform better. It is upon this problem that the research was carried out to find out how Business Intelligence Technology (BIT) technology can facilitate efficiency and effectiveness through innovation and absorption.

\subsection{LITERATURE REVIEW}

\subsection{Theoretical Perspective}

Systematic information management allows an organization to utilize business information efficiently. On the other hand, business information itself has no value for an organization if it is not utilized and new knowledge created. In the 1990s, a process view of information management began to gain currency (Davenport 1993; McGee \& Prusak 1993). One of the most well-known information management processes is Choo's (1995) information management cycle. From the author's perspective, Choo's information management process can be considered the basis for all business intelligence technology processes. Choo has defined information management as a nonstop cycle which has six phases: 1) identification of information needs, 2) information acquisition, 3) information organization and storage, 4) 
development of information products and services, 5) information distribution, and 6) information use.

Nonaka and Takeuchi's (1995) model of the organizational knowledge-creation process is also a suitable starting point for a business intelligence technology process. In most cases, business intelligence technology processes and techniques are used to acquire and analyze raw data and information. However, the main objective of the business intelligence technology process is to refine business data and information into useful and valuable knowledge and intelligence.

In this framework therefore, data and information are inputs of business intelligence technology processes and activities which produce knowledge and understanding related to important relationships and meanings. Thus, the outputs of the refinement process are knowledge and intelligence. Prior knowledge of an individual or an organization is needed to run that process, in other words, to refine the data and information into valuable knowledge and intelligence. The task of this refinement process is to add value to the acquired data and information and to make it useful for decision-makers by transforming it into knowledge and intelligence.

According to Pollard (1999), the objective of a business intelligence technology process is not only to produce general business information or knowledge. The goal of a process is also to create organization-specific intelligence solutions which enable more efficient utilization of business information.

A business intelligence technology process offers a practical way of managing business information and knowledge efficiently. The business intelligence technology process concept is understood as a continuous and systematic method of action by which an organization gathers, analyzes, and disseminates relevant business information to business activities (Pirttimaki \& Hannula 2003). Briefly, it is a process by which raw data and information are turned into usable and valuable knowledge and intelligence. According to Pirttimaki and Hannula (2004), a business intelligence technology process should consist of two main processes: An example of a business intelligence technology process (Pirttimaki \& Hannula 2004).

According to Pirttimaki and Hannula (2004), the processes can be reckoned as two separate processes that have their own phases, but which relate to each other. Namely, some phases of the processes can overlap each other. In the implementation process, business information needs are defined, relevant data and information are gathered, suitable tools are chosen, and finally the information gathered is stored. The utilization process has the following phases: utilization, analyses and observation, formulation of possibilities, dissemination of information and knowledge, decision-making, and changes in strategic and operational operations.

In the literature, several business intelligence technology process models have been presented (Thomas Jr. 2001; Vitt et al. 2002); Viva Business Intelligence technology Inc. 1998; Collins 1997; Kahaner 1996) and the literature also suggests that theoretical process models seem to be quite similar to each other (Pirttimaki \& Hannula, 2004). However, at the same time, these process models are also organization-specifc. The most significant differences between process models typically involve: the number of phases, the structure of cycles, sources of information, and methods of storing information (Pirttimaki \& Hannula, 2004). In addition, some models only focus on the external information and the business environment. Thus, 
necessary information is gathered only from external sources. Some models emphasize both external and internal information sources. These models highlight that the relevant understanding of an environment and of one's own business cannot be achieved if external information is not carefully structured and integrated with internal knowledge of an organization.

\subsection{Empirical Review}

Business Intelligence technology tools like decision support systems, Information Technology Infrastructure Flexibility, Business Intelligence Technologies, Organizational Absorptive Capacity and Innovation Competence were only available to senior executives (Shariat, 2007). With the advent of Internet and proliferation of Web 2.0 applications, business intelligence technology has been made accessible to employees at lower levels. While senior managers and analysts have access to more specialized Business Intelligence technology tools like digital dashboards, Online Analytical Processing (OLAP) and data mining, more junior employees can now also use search engines and subscribe to Really Simple Syndication (RSS) feeds to monitor competitors' actions for example press releases and customers' feedback on new media such as blogs.

The main purpose of Business Intelligence technology systems is 'to provide knowledge workers at various levels in organizations with timely, relevant and easy-to-use information' and 'to provide the ability to analyze business information in order to support and improve management decision making across a broad range of business activities' (Elbashir et al. 2008). Such systems primarily support analytical decision-making and are used in knowledge-intensive activities. These activities have three significant characteristics: they are often non-routine and creative (unclear problem space with many decision options) (Eppler 2006), their specifications cannot be predefined in detail, their outcome is uncertain and yet their success often brings innovations and improvements.

\section{The extent of intelligence technology on absorptive capacity}

\section{Absorptive capacities and Innovative competence of Business Intelligence technology}

The implementation of Business Intelligence technology systems can contribute to improved absorptive capacities and innovative competence in several ways, including faster access to information, easier querying and analysis, a higher level of interactivity, improved data consistency due to data integration processes and other related data management activities (e.g., data cleansing, unification of definitions of the key business terms and master data management). However, to understand how much the implementation of business intelligence technology systems actually contributes to solving issues of absorptive capacity and innovative competence in knowledge-intensive activities, it is important to be familiar with the problems that may arise. Lesca and Lesca (1995) emphasize the absorptive capacity of quality information problems that employees often face: limited usefulness of information due to an overload of information, ambiguity due to lack of precision or accuracy leading to differing or wrong interpretations, incompleteness, inconsistency, information that is not reliable or trustworthy, inadequate presentation and inaccessible information. The implementation of business intelligence technologies, involving both technology and organizational changes, should therefore contribute primarily to improving the quality of information content absorption since this can impact on the accomplishment of strategic business objectives through improved decision-making (Slone 2006, Al-Hakim 2007, Eppler 2006). More precisely, does the implementation of business intelligence technologies and 
related data management activities contribute in particular to improved absorptive capacity (i.e., quality of access to Business Intelligence technologies) or does it also focus adequately on the content aspects of Business Intelligence technologies quality, where the major problems of providing quality information lie. (Koronios and Lin 2007) identified some business intelligence technologies and activities, namely data cleansing, data integration, data tools and data storage architecture, as key factors influencing information quality. For example, data warehousing can imply an increase in content quality from the comprehensiveness and consistency criteria through data integration and cleansing, but it can also improve media quality since users do not have to search for data within different data sources and combine it to create information. In terms of data integration, the implementation of business intelligence technologies therefore contributes to both absorptive capacity of information content quality and innovative quality. Data management activities should result above all in BI technologies quality.

According to Koronios and Lin (2007), Business Intelligence technologies maturity can influence absorptive capacity content quality through a feedback loop: a better innovative insight into data allows the perception of errors at data collection which consequently improves data quality control at data collection. In terms of analytics, the higher maturity of analytical technologies (e.g., interactive reports, online analytical processing, data mining and dashboards) is expected to have an impact on both media quality and somewhat on content quality. Nevertheless, Eppler (2006) argues that technology mainly influences media quality and has limited possibilities of influencing content quality.

\section{Importance of business intelligence technology}

Whether the business is just on the verge of making it big or you want to make sure that you have a solid grip on the market that you already lead, you'll discover that you are going to be running into some real problems unless you take the time to evaluate your company's Business Intelligence technologies and how competitive it is with businesses that are already making use of the tools that go with this concept. Essentially, business intelligence technology is a measure of your company's capacity to get a better understanding of its commercial context, and without enough of it, you will soon find yourself in dire financial straits.

\section{Sustainable competitive edge}

Through sound data, personal and team insight as well as right corporate decisions, business intelligence technology can have a solid impact on company prosperity. Integrating predictive analytics within applications while building next generation user experiences is key. It allows a company to advance through measuring elements of business that can be improved.

It is also important for businesses to keep in mind that it is more than likely that their competitors are utilizing business intelligence technology tools. Not taking advantage of available data mining technologies can be detrimental to maintaining a competitive edge. Whether a business is seeking to grow, save money, or gain further company insight, business intelligence technology is an essential business tool for gaining granularity in regards to measuring and understanding different dimensions of the organization. Being able to extract meaningful data using existing business processes is an important part of what makes business intelligence technology work.

The key component behind what makes the data meaningful is that the company's data is organized and automatically generates reports that provide the different details necessary to 
make informed decisions and improve business. Businesses that utilize BI have a significantly greater potential to make discoveries that can lead to new or increased profits, smart decision-making, and lowering of organization costs through improved administrative management.

\section{Level of innovative competence}

Business intelligence technology as an Information Technology enabler to achieve organization's strategy

In recent years, Information Technology in general, and Business Intelligence Technology as a strategic framework, is becoming increasingly important in strategic management, supporting business strategies. Information Technology -enabled strategic management addresses the Information Technology role in strategy formulation and implementation processes. Drucker, (1954) the pioneer of management by objectives, was one of the first who recognized the dramatic changes Information Technology brought to management. Strategic management theories were largely geared towards gaining competitive advantages. Porter (1979) proposed a number of very influential strategic analysis models, such as the five-force model of competition, the value chain and generic competitive strategies. Porter (1979) said "The essence of strategy formulation is coping with competition" Many researchers have indicated the importance of Information Technology alignment with business strategy in order to enhance corporate strategy.

Strategic Alignment Model developed by Henderson and Venkatraman (1993) was one of the first models that described in an explicit way the interrelationships between business strategies and Information Technology strategies. This model is based on two main concepts strategic fit that recognizes the need to position the firm in an external marketplace where growth can take place, and functional integration which addresses how to best structure internal systems to execute the business strategy of the firm.

Information Technology alignment is not simply formulating Information Technology strategy to fit business strategy. It has to consider external forces and the environment uncertainty. Such alignment helps organizations becoming flexible organizations. As a result of accelerations in the rates of innovation and technological changes, markets evolve rapidly, products' life cycles get shorter and innovation becomes the main source of competitive advantage. Therefore, organizations seek flexibility to meet market demands. Drnevich et al. (2006) explained that flexibility-based perspectives evolved from Schumpeter's concept of creative destruction. Operationalization of these perspectives in strategic management is done through dynamic capabilities and real options views. Dynamic capabilities view refers to the firm's abilities to maintain and adapt its internal resources to environment changes to maintain sustainability of competitive advantages. It refers to the capability of acquiring new ways of competitive advantage. It involves continuous search, innovation and adaptation of firm resources and capabilities to uncover and tape new sources of competitive advantages. Real options view is effective in dealing with issues of uncertainty. It allows the firm to defer investment decisions until uncertainties are resolved. New Information Technology organizational adoption facilitates the transition into flexible organizations. Business Intelligence Technology is one of these new Information Technology frameworks that can help such transition. Business Intelligence technologies become a source of competitive advantages and differentiation. Tang and Walters (2006) mentioned that competitive 
advantage became a hot strategic management topic. They also view that generating new knowledge in a continued way is the single way to obtain competitive advantage.

There are many reasons for organization to adopt business intelligence technology systems in order to achieve organizations strategic goals.

- Business Intelligence technology is considered as an extension to corporate strategy activities. Herring (1988) considered that "Strategy can be no better than the information from which it is derived"

- Data analytics can be used effectively to build future business strategy.

- Data analytics and data mining could reveal hidden reasons for some deficiencies as well as possible high-yielding new investments.

- Corporations need to be sure that they are receiving the right information related to their long-term strategy.

Herring (1988) considered that business intelligence technology can help organizations in

- Supporting the strategic decision making process of the corporation.

- Supporting corporation Strength Weakness Opportunities Threats (SWOT) analysis

- Supporting strategic planning and processes.

All the mentioned benefits should provide organizations with sustainable competitive advantages over other organizations.

\section{The relationship between business intelligence technology, absorptive capacity and innovative competence}

Designing a successful business intelligence technology (BIT) process requires an understanding of the relationship between theoretical internal and external perspective of information. A challenge of business intelligence technology applications in the real world is the integration of internal and external information. In most cases, internal and external information is produced and disseminated by distinctive tools and processes. Despite the importance of effective business information analysis and dissemination in any organization, there is quite little theoretical or practical work which provides direct guidance on how both internal and external information can be utilized in business intelligence technology.

The theoretical aim of this research is to describe what kinds of roles internal and external information have in business intelligence technology. In addition, the study discusses the information-related concepts and briefly illustrates distinctions between data, information, knowledge, and intelligence. In addition, business information needs are discussed under this theoretical perspective of this research. The study is descriptive in nature and provides an insight into the issue concerned by means of a literature study.

Information is an important factor of production in the information society (Hannula 2001). In addition, more and more people work on occupations in which information and know-how are emphasized and different information and communication technologies are utilized (Sitra 1998). An organization can improve its competitiveness by developing new ways of action which are based on more efficient information management. The development of the information society requires that individuals, communities, and societies make their contribution to improving, sharing, and managing information. Thus, information is found to have a significant role in our present society. 
According to the classical definition, information is a well-defined true belief. This classic definition of information is based on the conceptions of the theory of knowledge, and it derives from Plato and other Greek philosophers (Hieta-Wilkman, 2002)

According to this classical definition, there are three conditions which information has to fulfill. First, there has always to be an explanation that information can never be a bare statement or claim. Second, there is always a demand for the truth. According to the third condition, a faulty belief cannot be information. However, it can be impossible to find a final truth. Thus, the classic definition can sometimes set too tough demands for information. Niiniluoto (1996) has compromised with the classical definition and practical problems and has reshaped the conception of information known as the critical realism of science.

According to Niiniluoto (1996), the condition of an explanation disentangles information from a belief; the condition of the truth disentangles the truth from a mistake, and the condition of the belief disentangles information from a hypothetical guess. Thus, the claim which has the best explanation can be called information.

These claims can also be called information when their truth is doubted. Namely, information is closing on the truth all the time and thus the quality of information sharpens with time.

In the literature, there are different definitions of data, information, knowledge, and intelligence (Aalto \& Jarenko 1984; Davenport \& Prusak 1998; Silver 2004; Thierauf 2001). In addition, there are various opinions regarding the mutual relation of these concepts. For example, knowledge is considered as a broader concept than information in most cases, and data is typically understood as the lowest level of an information hierarchy.

Davenport and Prusak (1998) define data as a set of separate and objective data elements. Thus, unanalyzed data, such as character strings, signals, numbers, texts, and photos, is the raw material of the first level in the information hierarchy. A receiver can understand the meaning of data only when data has a certain context.

According to Hintikka (1993), data can be defined as a part of raw data and information which has completely separated from the concept system. Information consists of separate pieces of data which are connected to each other on the second level. Stahle and Grönroos (1999) emphasize that a receiver can understand information only if information has value for him. Thus, information usually contains some kind of message which has some meaning or interpretation dependent on a receiver. On the third level, significance is imparted to information and information turns into human knowledge. However, information does not turn into knowledge until a receiver has processed the information and connected it to his own mental structure. Intelligence is created by dissections. Then, a receiver has a way of applying information and knowledge to solve problems or to carry out an assignment. Thus, intelligence is not only information but active knowledge how to apply the content of information.

Knowledge is categorized in numerous ways. Polanyi's (Nonaka \& Takeuchi, 1995) classification is one of the most well-known. Polanyi has categorized knowledge as tacit knowledge and explicit knowledge. This definition is based on Polanyi's observation that most of workers' know-how consists of empirical knowledge. Tacit knowledge is mainly hidden and personal and thus it is quite difficult to formalize, communicate, or share. Tacit knowledge is dependent on for example context, beliefs, experiences, values, and feelings. Explicit knowledge is exact and can be represented by numbers and words. Thus, explicit knowledge is easy to store and to disseminate formally and systematically. Whereas explicit 
knowledge is founded on making deductions rationally, tacit knowledge is based on individual experiences.

Thus, data and information can be considered as concepts close to explicit knowledge, and knowledge and intelligence as parts of tacit knowledge. (Committee for the Future 2001) Nonaka and Takeuchi (1995) have developed a five-phase model of an organizational knowledge-creation process. The process model illustrates how new knowledge is created, how explicit and tacit knowledge interact with each other, how knowledge can be disseminated, and how knowledge is integrated with an organization's own products, services, and systems. The integrated model encompasses the following phases: 1) the dissemination of tactical knowledge, 2) the creation of concepts, 3) the explanation of concepts, 4) the creation of a model, and 5) the adjustment of information.

According to Nonaka and Takeuchi (Huotari 2000), the model is easier to implement if for example the model is a part of an organization's strategy. In that way, it is easier to identify information needs of an organization. New ideas should emerge as results of the different thinking, conceptualization, and understanding of workers'. This increases an organization's ability to adapt, absorb and interpret information flexibly. In addition, an organization should have sufficient ability to respond to changes in the business environment.

The key to success is said to be the ability of an organization to recognize and utilize new external information gathered business intelligence technology tools and to read weak signals. In addition, an organization has to take advantage efficiently of existing information and knowledge inside an organization. In other words, an organization has to gather relevant business information from both external and internal sources of information. According to Aaltonen and Mutanen (2001), business information needs are the same as the lack of information, understanding, or know-how required at a specific moment. Lack of business information is an obstacle which becomes clear when an organization tries to fix problems or to utilize existing opportunities.

Naturally, every organization has its own specific business information needs. Because of this, it is difficult, if not impossible; to list business information needs generically. Business information needs can be roughly divided in half between external information and internal information (Uusi-Rauva 1994).

At the operative level, the significance of internal information is greater than that of external information. At the strategic level, external information is more important than internal information. In addition, Uusi-Rauva (1994) emphasizes that corporate management needs business information about: 1) the situation or facts which relate to the organization or the business environment, 2) quantitative andqualitative objectives, 3) methodsor means and factors by which the mode of operation of an organization can be changed to match objectives. It is important to remember that financial accounting is emphasized in UusiRauva's perspective. Namely, an organization also needs information about for example trends.

Stanat (1990) has categorized valuable information areas for business activities. From the author's perspective, Stanat's classification is one-sided. Namely, Stanat examines information needs only from the point of view of the external business environment. Vaarnas and Virtanen (2001) states that an organization needs more and more refined information about the business environment to reduce uncertainty in decision-making. They have classified business information under four headings: 
1. Organization-specific information, for example general information about an organization, business activities, and key success factors.

2. Industry-specific information, for example information about supply and demand situations and change processes in the industry.

3. General knowledge of the business environment; for example demographical, physical, international, legislative, political, economic, technological, social environment, and cultural information. General knowledge often relates to matters which organizations cannot have effect, but which have an influence on for example the entire industry.

4. Information related to a single organization or unit.

Pirttila (1997) has studied business information needs in a large Finnish company in her doctoral thesis. According to the thesis, some of the most important business information areas are the economic situation of competitors, the structure of ownership, new products, technological resources, marketing position, market behavior, organizational structure, investments, and capital expenditure plans. However, it is important to remember that defining actual information needs is probably the most difficult task in any business intelligence technology process or project, and that in knowledge-intensive work many information needs are "ad hoc" in nature.

It is apparent that both quantitative and qualitative business information is needed for successful decision-making. On the basis of the levels of information, business information can also be categorized into data, information, knowledge, and intelligence. According to Hannula and Pirttimaki (2004), this classification scheme is not pragmatic or practical enough. In order to identify the business information needs of managers in real business cases, a well-grounded practical framework is required. Hannula and Pirttimaki refer to three different dimensions for classifying business information needs as follows:

- The source of information: inside or outside the organization.

- The subject of information: inside or outside the organization.

- The type of information: quantitative or qualitative.

Hannula and Pirttimäki (2004) have depicted these three dimensions of business information needs as the dimensions of a cube. They state that the source of information can be presented as the $\mathrm{X}$-axis, the subject of the information as the Z-axis, while the type of information can be presented as the Y-axis. Thus, the cube of business information is based on the sources, the subjects, and the types of business information, and the actual cube of business information is constructed by putting these axes together.

Hannula and Pirttimäki (2004), state that the cube of business information provides an illustrative tool for approaching different business information needs. In addition, the cube can also be used to analyze organizations including business intelligence technology related vendors and service providers, as well as their offerings and position within the marketplace.

Business intelligence technology (BIT) technology is a managerial concept and tool that is used to help an organization to manage business information and to produce up-to-date knowledge and intelligence for operative and strategic decision-making (Ghoshal \& Kim 1986; Gilad \& Gilad 1986).

In the literature, there is no generally accepted conception regarding what business intelligence technology is; on the contrary, each author has promoted his own idea of its 
connotations. Actually, the term business intelligence technology is dualistic. The term refers to 1) the relevant information and knowledge that describe the business environment, an organization itself, and its state in relation to its markets, customers, competitors, and economic issues and 2) the process that produces the intelligence described above. In addition, the information technology based systems used in analyzing raw data and information and in storing and reporting valuable knowledge and intelligence are also considered an important part of business intelligence technology (Moss \& Atre 2003). Thierauf (2001) considers that business intelligence technology is an effective aid to decision-makers for getting the whole picture of an organization's own capabilities and the business environment.

\subsection{METHODOLOGY}

\subsection{Formulation of development programs}

In addition, business intelligence technology (BIT) aims to increase the quality of strategic and operative planning and to decrease the time used for decision-making. Thomas Jr. (2001) has defined that the most significant goals of business intelligence technology are; avoiding surprises, identifying threats and opportunities, decreasing reaction time, out-thinking the competition, protecting intellectual capital and understanding where an organization is defenseless. Halliman (2000), for one, argues that business intelligence technologies can mean any business information that facilitates decision-making and managing the future.

Business information can be exploited in business intelligence technology and its sub processes, through competitive intelligence. For example, there are two different dimensions to support the idea: the source of information can be presented as the $\mathrm{X}$-axis and the form of information as the $\mathrm{Y}$ axis.(Hervonen 2004.). It is important to take into account that the perspective of business intelligence technology is usually more "business-oriented" than knowledge management's perspective. According to Hervonen (2004), there are two schools on business intelligence technology thinking:

1) a quantitative view and 2) a qualitative view. The first emphasizes internal information. The basis of the quantitative view is that the structured business information is gathered from an organization's internal sources. Thus, business intelligence technology focuses on the internal information in this way of thinking. The other outlook stresses the external information. The unstructured information regarding competitors and markets forms a basis for competitive intelligence and business intelligence technology.

On the other hand, it does not really matter where the information comes from as long as the quality of information is good enough (Hannula \& Pirttimäki 2004). Namely, a decision maker needs business information from different sources and subjects, including those inside and outside an organization. Required information can be quantitative or qualitative in nature, as can be seen from the figure from Hervonen above. From the author's perspective, business information from several appropriate sources and about different subjects is required in order to paint a holistic picture of an organization's business activities and its business environment. 
European Journal of Technology

ISSN 2520-0712 (Online)

Vol.1, Issue 2 No.4, pp55-73, 2017

WWW.ajpojournals.org

\subsection{RESULTS AND DISCUSSIONS}

The profile attributes of the respondents revealed that Majority of the respondents were male with a high proportion of respondents being between the age bracket of 30-39, Predominant in the length of service were those workers serving below 3 years and most of the respondents were degree holder.

University staffs have some strengths and weaknesses in terms of business intelligence technology absorptive capacity and innovative competence. For instance, In terms of the extent of Business Intelligence technology on absorptive capacity,University staffs have ability to complement knowledge about their clientele and at the same time, the enthusiasm about acquiring business intelligence technology. The weaknesses however, include among other things, the fact that multiple channels for acquisition of business intelligence technology are not available to staff; and failure for staffs to possess the required speed and intensity to acquire business intelligence technology.

As far as level absorptive capacity is concerned, it was found out that majority (52.2\%) of the respondents highly agreed that University staffs have the capacity to analyze any information acquired. Another $49.2 \%$ of them also highly agreed that University staffs have the capacity to interpret data about their clientele. However, at least $46.2 \%$ of the respondents were of the view that University staffs have the support systems (software) used as tools. A significant proportion $(72.2 \%)$ of the respondents indicated that University staffs have the determination to utilize data about their clientele. Another $50.9 \%$ of them indicated that University staffs have the skills required to be innovative or create new knowledge.

In terms of level of innovative competence, majority $(60.1 \%)$ of the respondents highly agreed that University staff has a wide base of business intelligence -related technology. Another $49 \%$ of them also highly agreed that University staffs' basic business intelligence technology can enable them recognize new knowledge. A correspondingly moderate $(30.5 \%)$ proportion of the respondents agreed that University staffs' basic business intelligence technology can enable them determine the absorptive capacity n paths. However, $58.3 \%$ of the respondents were of the view that University staffs' basic business intelligence technology can enable them discover new value creation and also 55.5\% of them agreed that University staffs' basic business intelligence technology can enable them discover new opportunities.

Lastly, it was found out that majority $(62 \%)$ of the respondents agreed that University staff has the capacity to absorb business intelligence -related technology. Another $66.6 \%$ of them also agreed that University staffs possess the capacity to customize existing products or service. A correspondingly higher $(68.5 \%)$ proportion of the respondents agreed that University staffs possess the capacity to develop new innovative competencies. However, at least $44.4 \%$ of the respondents were of the view that University staffs do not have the capacity to create new products or services. Another $44.4 \%$ of them agreed that University staffs have the support of top management while $47.2 \%$ of them agreed that University has a supportive culture.

The business intelligence technology (BIT) market is undergoing a revolution. Its dynamic nature can be daunting to organizations trying to evaluate, purchase and deploy business intelligence technology (BIT) to improve their business processes. Despite the advances, research shows high levels of dissatisfaction with and immaturity in business intelligence technology (BIT) capabilities within organizations. Challenges remain to spread absorption 
of business intelligence technology (BIT) among a wider audience and improve its use in organizations. We have recently seen progress in integrating information management and analytics into a single framework, but more work remains. The use of collaboration will help improve dialogue and delivery of information to business users. Organizations can also adopt and support mobile business intelligence technologies (BIT) to enhance productivity and broaden the reach of innovativeness competencies.

Technology exists today to apply analytics to all information regardless of volume, data type and origin. However, organizations still struggle to evaluate alternatives for supporting large data sets including location data, event data and machine-generated data, all of which can contribute to more accurate analyses of their business processes. Also as the proportion and volume of unstructured data grow, users will need to incorporate text analytics to complement structured data analysis. On top of these challenges businesses now operate at Internet speeds and must analyze data and events as they are created or miss fleeting market opportunities.

Organizations must develop their analytical capabilities further not just to provide data but to optimize business decisions. To enhance decision-making and improve business outcomes, they must move beyond historical analysis to look forward through planning, forecasting and predictive analysis. And the dramatic rise in popularity of social media creates another source of information to incorporate in the decision-making process and another channel for involving larger groups in feedback processes.

There are five underlying technology innovations impacting business intelligence technology (BIT) and creating the aforementioned revolution: cloud computing, mobile technologies, social media, and analytics of more types over more data, and collaboration. Research has identified the five areas as the business technology revolution and all are directly relevant to business intelligence technology (BIT). As previously pointed out in the literature review, clouds are raining corporate data, cloud-based business intelligence technology (BIT) systems are rising in popularity. So are other types of cloud applications, which means that more and more of the data organizations need to analyze will reside in the cloud. This study examined the issues of absorptive capacity and innovative competencies as a prerequisite to adoption of the business intelligence technology (BIT) in organizations such as Universities are just about to get under way.

Mobile technologies including intercom service are invading the enterprise through employees. As mobile devices have developed more capabilities and larger form factors appear in tablets, business users on the go are demanding access to business intelligence technology (BIT) wherever they may be. Some software vendors and innovative enterprises have recognized these devices as vehicles to enable front-line business intelligence technology (BIT) and decision-making capabilities. More organizations are supporting their business users and realizing benefits of both broader business intelligence technology (BIT) adoption and enhanced productivity of their workforce.

Social media has created several new challenges for businesses and their use of business intelligence technology (BIT). First, this rich source of information can help companies understand customers and prospects, their characteristics, their opinions and their experiences in interacting with the organization. But analyzing unstructured social media content is new to most organizations. Second, social media can also play a role in collaborating on business intelligence technology (BIT)-aided decision-making processes (discussed below). Third, 
social media is a source of information and opinions about the business intelligence technology (BIT) products and services organizations may be evaluating. Finally, the combination of social media and mobile technologies is increasing demand for real-time data and instant analysis of it.

Collaboration technologies, as applied to business intelligence technology (BIT), are not the same as social media. Social media such as twitter, chatter, or Tibbr may be used as part of a social process, but collaboration is more than just a conversation. It includes workflow and approval processes as well as tracking communication associated with business intelligence technology (BIT) decision-making. Social media can be the delivery vehicle for some of the information and conversation tracking, but it is not sufficient on its own. Innovative organizations recognize the processes involved in business intelligence technology (BIT) are as important as the technology and take steps to provide collaborative support to their business intelligence technology (BIT) activities. The rise of social media has helped raise awareness of collaboration in general, but many organizations are still confused about how to apply collaboration to the business intelligence technology (BIT) process.

At the core of business intelligence technology (BIT), analytics have evolved beyond simple historical analysis. More advanced analytic techniques have been available for decades but are still not widely embraced. For example, this research shows that only $25 \%$ of University staff are using planning and forecasting on their BIT applications. However, in business areas such as finance, planning with what-if and scenario modeling has been common for years, in part because the volumes of data were smaller and more easily managed. In other specific business functions such as fraud detection, predictive analytics have played a significant role for years despite their cost and complexity because of the magnitude of the savings that could be achieved. With these business areas paving the way and with the advent of information management technologies that can marry larger volumes of data with more powerful analytics, organizations can now deploy these capabilities across a much wider range of business problems. In short, while the challenges are great, so are the opportunities. It is an exciting time in the business intelligence technology (BIT) market.

\subsection{CONCLUSIONS AND RECOMMENDATIONS}

\subsection{Conclusions}

Although University staffs have reasonable ability to complement knowledge about their clientele and the enthusiasm to acquire business intelligence technology (BIT), the university does not have the multiple channels and the required speed for absorb of business intelligence technology (BIT) related knowledge. Despite having the support systems used as tools, the skills required to create new knowledge and the determination to utilize data about its clientele, the university staffs do not have the capacity to analyze acquired information nor interpret data about the clientele.

The University staffs do not have a wide base of business intelligence technology (BIT) and the staffs' basic business intelligence technology (BIT) skills cannot enable them recognize new knowledge even though their basic business intelligence technology (BIT) can enable them determine the absorptive capacity path, discover new innovative competencies and discover new opportunities. TheUniversity staff has the capacity to absorb customer related knowledge, customize existing products and services although they cannot create new ones due to lack of support from top management and a supportive culture. 
European Journal of Technology

ISSN 2520-0712 (Online)

Vol.1, Issue 2 No.4, pp55-73, 2017

\subsection{Recommendations}

There is need to train University staff in order to build capacity to absorb, analyze and manage information. There is need to improve on the staffs' basic business intelligence technology (BIT) skills and innovative competencies in the use of tools used in business technology systems. The university's top management needs to support the staff in various ways that will not only build their absorptive capacity but improve upon their skills and competencies in preparation for adoption of business intelligence technology (BIT) in the university. The university should cultivate and maintain a supportive culture for staff to unleash their potentials in the use of business intelligence technology (BIT). Further research should be carried out on the requirements for adoption of business intelligence technology (BIT) in organizations.

\section{REFERENCES}

Amabile et al. (1996) (Amabile, T. M., R. Conti, et al. (1996). "Assessing the work environment for creativity." Academy of Management Journal 39(5): 1154-1184) propose:

Arpan Kumar Kar, Ashis Kumar Pani and Supriya Kumar DeKumar Kar A., Kumar Pani A., Kumar De S.

A Study on Using Business Intelligence for Improving Marketing Efforts Business Intelligence Journal - July, 2010 Vol.3 No.2 150.

Barras, R. (1984). "Towards a theory of innovation in services". Research Policy_15: 161-73.

Byrd, Jacqueline (2003). The Innovation Equation - Building Creativity \& Risk Taking in your

Organization. San Francisco, CA: Jossey- Bass/Pfeiffer - Aprint.

Choo, C. W. 1995. Information Management for the Intelligent Organization: The Art of Scanning the Environment. Medford (N.J.), Information Today Inc.

Cohen and Levinthal (1990), "Absorptive capacity: A new perspective on learning and innovation", Administrative Science Quarterly, Volume 35, Issue 1 pg. 128-152

Cabral, Regis (1998). "Refining the Cabral-Dahab Science Park Management Paradigm". Int. J. Technology Management, 16 (8): 813-818.

Cabral, Regis (2003). "Development, Science and". In Heilbron, J.. The Oxford Companion to the History of Modern Science

Collins, R. J. 1997. Better Business Intelligence. How to Learn More about Your Competitors.

Management Books, Astron On-Line, Letchworth 
Cohen and Levinthal (1989), "Innovation and learning: The two faces of R\&D", The Economic Journal, Volume 99, September pg. 569-596.

Davenport, T. H. 1993. Process Innovation: Reengineering Work through Information Technology. Harvard Business School Press, Boston, Massachusetts.

Elbashir, M.Z., Collier, P.A. \& Davern, M.J. (2008). Measuring the effects of business intelligence systems: the relationship between business process and organizational performance. International Journal of Accounting Information Systems, 9(3), 135153.

E. Turban, J. E. Aronson, T. P. Liang, R. Sharda, Decision Support and Business Intelligence Systems,8th edition, Pearson Prentice Hall, 2007.

Eppler, M.J. (2006). Managing information quality: increasing the value of information in knowledge intensive products and processes (2nd ed.). Berlin: Springer.

Hannula, M. 2001. Onko tietoyhteiskunnassa tilaa tuottavuusajattelulle Tyoelaman tutkimus 2/2001, pp. 26 - 29. (In Finnish.)

International Conference \& Exhibit, March 22 - 25, Boston, Massachusetts, USA. Hervonen, A. 2004.

Johdanto kurssiin sekä Business Intelligence -terminologiaan. Handout. Helsinki School of Economics. (In Finnish.) Journal, Volume 99, September pg. 569-596.

\& Lin, S. (2007). Information quality in engineering asset management. In L. Al-Hakim, (Ed.), Information quality management: theory and applications (pp. 221-251). Hershey, PA: Idea Group Publishing.

Lesca, H. \& Lesca, E. (1995). Gestion de l'information, qualité de l'information et performances del'entreprise. [Information management, information quality and business performance.] Paris: Litec. LB; Verron Haynes (2010) (notes)

McGee, J. V. \& Prusak, L. 1993. Managing Information Strategically. John Wiley \& Sons,New York.Moss,

M. Shariat, R. Jr. Hightower, "Conceptualizing Business Intelligence Architecture", Marketing Management Journal, Volume 17, Issue 2, pp. 40 -46, 2007.

M. E. Porter, "Competitive Strategy-Techniques for Analyzing Industries and Competitors", NewYork: Free Press. 1980 New York: Oxford University Press. pp. 205-207.

Pollard, A. 1999. Competitor Intelligence, Strategy, Tools and Techniques for Competitor Advantage. Financial Times, Prentice Hall Publishing, London.

Raven, J., \& Stephenson, J. (Eds.). (2001). Competency in the Learning Society. New York: Peter Lang 
European Journal of Technology

ISSN 2520-0712 (Online)

Vol.1, Issue 2 No.4, pp55-73, 2017

Sitra. 1998. Elämän laatu, osaaminen ja kilpailijakyky. The Finnish Fund for Research and

Development. Hakapaino Oy, Helsinki. (In Finnish.)

Slone, J. P. (2006). Information quality strategy: an empirical investigation of the relationship between information quality improvements and organizational outcomes. Unpublished doctoral dissertation. Capella University, Minneapolis, Minnesota, USA>

Vitt, E., Luckevich, M. \& Misner, S. 2002. Business Intelligence: Making Better Decisions Faster. Microsoft Press, Washington

Viva Business Intelligence Inc. 1998. Developing a Business Intelligence Process: Viva Business Intelligence - Cycle Approach. Pro-How Paper, Helsinki. Vol. 2

Zahra and George (2002), "Absorptive Capacity: A Review,Reconceptualization, and Extention",

Academy of Management Review,Volume 27, Issue 2,pg.185-203 ACM, SIGMOD Intl. Conf. Management of Data, Washington.

Brooks NAL (1989). Marketing technology: new marketing information systems enhance service and profitability. Bank Administration. 65(5): 52-54.

Comanor WS, Wilson TA (1967). Advertising, Market Structure, and Performance. Review of economic statistics. 49 (4): 423-440.

DeSarbo WS, Hildebrand DK (1980). A Marketer's Guide to Log-Linear Models for Qualitative Data Analysis. Journal of Marketing. 44 (summer): 40-

Duda RO, Hart PE, Stork DG (2001). Pattern Classification. Wiley publications. Dunham MH (2003). Data mining: Introductory and advanced topics. Pearson Education.

Gartner Research (2008). Findings: Social Network Analysis Is coming into the Limelight. ID Number: G00157280.

Green PE (1978). An AID/Logic Procedure for Analyzing Large Multi-way Contingency Tables. Journal of Marketing Research. 42(4): 92-100.

Gronroos C (1990). Service Management and Marketing: Managing the Moments of Truth in Service

Competition. Lexington Books, Lexington, MA. 2010149 Haeckel SH, Nolan RH (1993). Managing by wire. Harvard Business Review. pp. 122 - 132.

Han J, Kamber M (2001). Data Mining: Concepts and Techniques. 2nd edition, Morgan Kaufmann Publishers. 
Holland PC, Naude P (2004). The metamorphosis of marketing into a problem. The Journal of Business \& Industrial Marketing. 19(3): 167-178.

Holsheimer M, Kersten M, Mannila H, Toivonen H. (1995). A perspective on databases and data mining. In 1st Int. Conf. Knowledge Discovery and Data Mining.

Houtsma M \& Swami A (1995). Set-oriented mining of association rules in relational databases. Proceedings, 11th Int. Conf. Data Engineering.

Kaldor N, Silverman R (1948). A Statistical Analysis of Advertising Expenditures and of the Revenue of the Press. Cambridge University Press.

Kotler P, Keller KL (2006). Marketing Management. 12th Edition, Prentice hall, New York.

Levin N, Zahavi J (1999). Continuous predictive modeling - A comparative analysis. Journal of Direct Marketing. 12(2): 5-22.

Moller KE (1994). Inter-organizational marketing exchange: Meta-theoretical analysis of currentresearch approaches. Research Traditions in Marketing. Kluwer Academic Publishers, Boston.

Moriarty RT, Swartz GS (1989). Automation to boost sales and marketing. Harvard Business Review. 67(1): 100-108.

Naude P, Holland CP (1996). Business to business marketing. Relationship marketing, theory and practice. Paul Chapman Series, 40-54.

Peacock PR (1998a). Data mining in marketing: Part 1. Mmarketing Management. 6(4): 8-19.

Peacock PR (1998b). Data mining in marketing: Part 2. Marketing Management. 7(1): 14-26.

Perreault WD, Barkswale HC (1980). A Model-Free Approach for Analysis of Complex Contingency Data in Survey Research. Journal of Marketing Research. 17: 503-515.

Rayport JR, Sviokla JJ (1995). Exploiting the virtual value chain. Harvard Business Review. Nov-Dec: $75-85$.

Sheth JN, Gardner DM, Garrett DE (1988). Marketing Theory: Evolution and Evaluation. John Wiley \& Sons, New York.

Telser GL (1961). How muchdoes it Pay Whom to Advertise. American Economic Review. 51: 194-205.

The World Advertising Research Center (2001). World advertising expenditure. International Journal of Advertising. 20: 266 - 268.

Webster FE Jr. (1992). The changing role of marketing in the corporation. Journal of Marketing. 56(4): 1-17.Business Intelligence Journal - July, 2010 Vol.3 No. 